\title{
Russian discourse markers vidimo and po-vidimomu ('apparently'): synchronic and diachronical semantics
}

\author{
Anna A.Zalizniak \\ Institute of Linguistics of the Russian Academy of Sciences / \\ 1, B. Kislovskij Ln., Moscow, 125009, Russia \\ Institute of Informatics Problems of the Russian Academy of Sciences / \\ 44-2 Vavilova St., Moscow, 119333, Russia \\ anna.zalizniak@gmail.com
}

\begin{abstract}
The article analyzes the meaning of Russian discursive words vidimo and po-vidimomu ('apparently'), and reconstructs the ways of their semantic evolution over the past two centuries. It is shown that the meaning of an inference made by the speaker on the basis of some data, which is the only one for both words in modern language, arose in different ways. The semantic evolution of both words includes the the replacement of the meaning of visual perception with the meaning of epistemic evaluation and the acquisition of egocentric semantics. The word vidimo initially served as a marker of a true visual impression; the word po-vidimomu which initially included an interpretative component, acquired the meaning of a potentially false judgment, which was subsequently lost. The research is based on texts included in the Russian National Corpus (www.ruscorpora.ru).

Key words: Russian language, semantics, semantic evolution, discourse markers, visual perception, epistemic evaluation, inference
\end{abstract}

DOI: $10.28995 / 2075-7182-2021-20-720-728$

\section{Дискурсивные слова видимо и по-видимому: актуальная и диахроническая семантика ${ }^{1}$}

\author{
Анна А. Зализняк \\ Институт языкознания РАН /125009 Москва, Б. Кисловский пер. 1; \\ ФИЦ ИУ РАН /119333 Москва, ул. Вавилова 44-2 \\ anna.zalizniak@gmail.com
}

\begin{abstract}
Аннотация
В статье анализируется значение русских дискурсивных слов видимо и по-видимому и восстанавливаются пути их семантической эволюции на протяжении двух последних веков. Демонстрируется, что значение умозаключения, сделанного говорящим на основании каких-то данных, являющееся в современном языке единственным для обоих слов, возникло разными путями. Семантическая эволюция обоих слов включает замену значения зрительного восприятия на значение эпистемической оценки и приобретение эгоцентрической семантики. При этом слово видимо исходно служило маркером истинности зрительного впечатления; слово по-видимому, изначально включавшее компонент интерпретации зрительных данных, приобрело значение потенциально ложного предположения, которое впоследствии было утрачено. Исследование проведено на материале текстов Национального корпуса русского языка (www.ruscorpora.ru).

Ключевые слова: русский язык, семантика, семантическая эволюция, дискурсивные слова, зрительное восприятие, эпистемическая оценка, инференция
\end{abstract}

\footnotetext{
${ }^{1}$ Работа выполнена при частичной поддержке РФФИ, грант № 19-012-00505.
} 


\section{1 Вводные замечания}

Дискурсивные слова видимо и по-видимому в современном русском языке практически синонимичны: оба обозначают умозаключение (предположение), сделанное говорящим на основании каких-то данны ${ }^{2}$. С функционально-стилистической точки зрения они различаются по двум параметрам: видимо преобладает в художественной и устной речи, а по-видимому - в научно-деловой и письменной ${ }^{3}$. Однако в течение всего XIX и почти до конца XX века оба эти слова имели более широкий круг значений, среди которых были существенно различные.

Исследователями неоднократно отмечался тот факт, что если что-то «видно», то это может означать что это так и есть и что это, наоборот, «только кажется» (ср., напр. [10: 167, 172]; [4: 95]). Ю.Д.Апресян [1: 40] отмечает, что значение «истинного» и «ложного» перцептивного впечатления может совмещаться в пределах одной лексемы, иллюстрируя этот тезис глаголами выллядеть, показаться, посльшиаться. Значение «ложного впечатления» имеют некоторые слова, производные от основы вид-, ср. привидеться, видимость, а также выражения с виду (он хорош, да зелен), сделать вид; это значение, помеченное как «уходящее», выделяется также в [2: 123] у прилагательного видимый (ср. видимое благополучие).

Эта двойственность возникает из-за того, что зрительное восприятие по своей природе включает элемент интерпретации - которая может оказаться правильной или неправильной. Интерпретативный компонент в разных условиях обнаруживает себя в большей или меньшей степени. Так, сам глагол видеть в конструкции с изъяснительным придаточным с что (за исключением контекста синхронного репортажа) вводит умозаключение - в отличие от конструкции с как, вводящей описание самой воспринимаемой зрительно ситуации ${ }^{4}$. Это умозаключение представляет собой результат интерпретации данных - как перцептивных, так и любых других, тем самым в конструкции с придаточным с что глагол видеть может утрачивать компонент зрительного восприятия, ср.:

(1) Видя, что толку не доищешься, Фекла поспешно подобрала подол и продолжала путь. [Д. В. Григорович. Бобыль (1847)]

(2) Урок был большой и трудный, я ничего не знал и видел, что уже никак не успею хоть что-нибудь запомнить из него < ...>. [Л. Н. Толстой. Отрочество (1854)]

(3) Сейчас я вижу, что в случившемся было много иррачионального, но был, между прочим, момент и вполне рациональный. [Вера Белоусова. Второй выстрел (2000)]

Это умозаключение принимается субъектом за истинное; значения ложного впечатления глагол видеть выражать не может.

Обратимся теперь к значению производных от глагола видеть дискурсивных слов видимо и по-видимому.

\section{2 Видимо}

В словаре [6: I, 174] у видимо выделяется два значения: «устар. нареч. заметно, явно», иллюстрируемое примером (4), и «в знач. вводн. сл. вероятно, по-видимому», пример (5).

\footnotetext{
${ }^{2}$ В этот ряд входит также близкое по значению, но более разговорное (и обладающее рядом других особенностей) слово видно, а также еще более специфическое видать, которые в данной статье рассматриваться не будут. О словах видимо, по-видимому, видно см. также [12], [8], [13].

${ }^{3}$ По данным НКРЯ слово видимо употребляется в художественных текстах в 1,25 раза чаще, чем в официальноделовых, публицистических и научно-популярных (по классификатору НКРЯ; соответственно, 121,2 ipm и 97 ipm), слово по-видимому, наоборот, в 1,35 раза реже (соответственно, 52,3ipm и 70,6 ipm). Причем эти обобщенные подсчеты существенно нивелируют реальную картину: некоторые авторы (напр. Бунин, Чехов, Платонов, Шолохов) в своих художественных текстах слова по-видимому вообее практически не употребляют. С другой стороны (по подсчетам М.Ю.Михеева, устное сообщение), в художественной прозе Тынянова слово по-видимому имеет частоту $82 \mathrm{ipm}$, а в научных текстах - $698 \mathrm{ipm}$, т.е. в научных текстах встречается в 8,5 раз чаще. В письменной речи слово видимо употребляется в 1,3 раза реже, чем в устной (соответственно, $108 \mathrm{ipm}$ и $142 \mathrm{ipm}$ ), а слово по-видимому, наоборот, в письменной речи встречается в 1,6 раза чаще, чем в устной (соответственно, $62 \mathrm{ipm}$ и $38,5 \mathrm{ipm}$ ).

${ }^{4}$ Об этом различии конструкций с что и с как см. [9: 87], [14: 451].
} 
(4) Казалось, готовилась гроза; черные тучи росли и ползли по небу, видимо меняя свои дымные очертания. (Тургенев. Первая любовь)

(5) Он взял Подгорина под руку и все уводил его вперед, видимо собираясь поговорить с ним. (Чехов. У знакомых)

В первом значении слово видимо является наречием образа действия (т.е. 'таким образом, что это заметно, ${ }^{5}$ и указывает на реальное зрительное восприятие названой в предложении ситуации (ср. пример (4), где тучи меняют свои очертания именно видимо, т. е. явно). Это наречие, в свою очередь, производно от пассивного причастия в составе глагольной формы, ср:

(6) Как император, так и императрица были очень довольны своим коронованием, и это довольство было видимо для всех. [П. И. Ковалевский. Император Павел I (1900-1910)]

В значении наречия образа действия слово видимо несет на себе фразовое ударение и является маркером истинности описываемого впечатления. Это значение, диахронически исходное, оставалось актуально в течение XIX в., ср.:

(7) Она подала мне свою руку, холодную, слабую и дрожащую; грудь ее видимо подымалась и опускалась [Н. М. Карамзин. Письма русского путешественника (1793)]

(8) Провидение сохранило Россию. Можно сказать, что Оно видимо хранит и начинающееся царствование. Какой день был для нас 14-го числа! В этот день всё было на краю погибели: минута, и всё бы разрушилось. [В. А. Жуковский. Письмо к А.И.Тургеневу (1825)]

(9) Его некрасивое, но выразительное лицо, с глазами, блестящими умом и энергией, было видимо взволновано. [Н. Э. Гейнце. Коронованный рыцарь (1898)]

На протяжении XX в. его употребительность постепенно сокращается, и для языка XXI в. оно является безусловно устаревшим, хотя и продолжает изредка встречаться, ср.:

(10) Когда видимо стало распадаться на части живое тело Державы, казавшееся могучим, $<\ldots>$ он не приметил начавшегося разрушенья - и саморазрушенья тем более. [В. Г. Галактионова. 5/4 накануне тишины // «Москва», № 11, 12. 2004]

Во втором значении видимо является вводным словом, указывающим на ментальный акт предположения ${ }^{6}$; это предположение может касаться реконструируемой говорящим причины некоторого известного говорящему положения дел (ср. в примере (11): замолчали - потому что устали), в том числе - цели субъекта описываемого действия, ср. (описание ситуации, относительно причины/цели которой делается предположение, выделено подчеркиванием):

(11) Они еще немного о чем-то поговорили и, видимо устав от разговоров, еды и вина, замолчали. [Сергей Шикера. Египетское метро // «Волга», 2016]

(12) Отец не стал заканчивать фразу, видимо, предлагая теперь высказаться сыну. [Ю. И. Лунин. Три века русской поэзии // «Волга», 2016]

(13) Она вообще всегда старалась держать меня в стороне от своей банкирской жизни, видимо, рассчитывая, что мыс с Петькой будем только стричь купоны, занимаясь при этом своими делами. [Вера Белоусова. Второй выстрел (2000)]

(14) В результате мне всё-таки дали роль, видимо, для очистки совести. [Сати Спивакова. Не всё (2002)]

(15) Однако он снова, 一 видимо, для того, чтобы себя испытать, - взбивал свою тощую подушку, ложился на усыпанную колючими крошками койку, открывал книгу [Ю. И. Лунин. Три века русской поэзии // «Волга», 2016]

Слово видимо в этом значении является безударным (и характеризуется определенным интонационным контуром, характерным для вводных слов); на письме вводные слова обычно выделятся запятыми. Компонент зрительного восприятия оказывается в нем утрачен: здесь

\footnotetext{
${ }^{5} \mathrm{Cp}$. значение 2 прилагательного видимый в [2: 123]: 'такой, наличие которого заметно': Они поссорились без видимых причин.

${ }^{6}$ Ср. замечание Н.Д.Арутюновой [3: 816], касающееся, в том числе, слов видимо и по-видимому: «[...] попадая в позицию вводного слова, почти все предикаты истинности, необходимости, восприятия и знания получают значение предположительности».
} 
происходит тот же семантический сдвиг, что и в самом глаголе видеть в конструкции с придаточным с что (ср. выше): видимо вводит умозаключение, сделанное на основании какихто данных, в общем случае не связанных с реальным зрительным наблюдением, ср. примеры (11)-(17).

(16) В молодости он, видимо, был страстно в неё влюблен. [Сати Спивакова. Не всё (2002)]

(17) Что ж, страдающим от пыльцы аллергикам отныне, видимо, следует взять за привычку ежедневно читать о ботанике в Интернете. [Дмитрий Анохин. Березовая каша для аллергиков // «Вечерняя Москва», 2002.05.16]

Итак, слово видимо имеет два отчетливо противопоставленных значения: значение маркера истинности зрительного впечатления и маркера предположения, сделанного на основании аргументов любого рода. Эти два значения, однако, в определенных условиях могут оказаться трудноразличимы - и именно такого рода случаи обеспечивают соответствующий семантический переход. Наиболее показательным в этом отношении является контекст описания чужого внутреннего состояния, обнаруживаемого по каким-то внешним признакам.

Так, в примере (18) из воспоминаний брата Ф.М.Достоевского ситуация 'его лицо пылало счастьем' не может быть результатом умозаключения: это именно непосредственно наблюдаемая ситуация, и тем самым видимо здесь имеет перцептивное значение

(18) Раз как-то помню еще в начале моего пребывания в Москве, приезжает утром к Карепиным Александр Павлович Иванов; все лицо его было радостное и, видимо, пьлало счастием. [А. М. Достоевский. Воспоминания (1896)]

В примере (19) видимо выражает, наоборот, предположение:

(19) Дискретный Билль, - который, видимо, гордился тем, что мог творить чудеса одной рукой, - принес открытые им жестянки пива. [В. В. Набоков. Лолита [автоперевод с английского] (1967)]

Однако относительно примеров (20)-(23) трудно сказать, вводит ли слово видимо описание непосредственно наблюдаемой ситуации или предположение, сделанной на основании ее наблюдения.

(20) < ..> молодой человек лет двадцати, подслеповатый и белокурый, с ног до головы одетый в чёрную одежду, видимо робел, но язвительно улыбался... [И. С. Тургенев. Гамлет Щигровского уезда (1849)]

(21) - Еще бы отказаться, - пробасил Ракитин, видимо сконфузивиись, но молодцевато прикрывая стыд, - это нам вельми на руку будет, дураки и существуют в профит умному человеку. [Ф. М. Достоевский. Братья Карамазовы (1880)]

(22) В конце июля 1860 года я по старой памяти отправился из Новоселок на Неручь на охоту, избрав главным центром сельцо Ивановское, имение моего зятя А. Н. Шеншина, женатого на родной сестре моей Любиньке. Они, видимо, обрадовались моему приезду и старались по возможности устроить меня поудобнее [А. А. Фет. Мои воспоминания / Часть I (18621889)]

(23) - Примите меры, доктор, умоляю, - истерически крикнула девица. На лестницу выбежал секретарь филиала и, видимо, сгорая от стыда и смущуения, заговорил, заикаясь: [М. А. Булгаков. Мастер и Маргарита, часть 1 (1929-1940)]

\section{3. По-видимому}

Слово по-видимому в современном русском языке имеет единственное значение, а именно, оно касается положения дел, относительно которого говорящей не располагает знанием и на

\footnotetext{
${ }^{7}$ Выделение его запятыми здесь очевидно является ошибочным.
} 
основании каких-то имеющихся в его распоряжении данных, формирует мнение, что дела обстоят именно так ${ }^{8} . \mathrm{Cp}$.:

(24) Старушка, по-видимому, привыкщая к таким странным выходкам, смотрела на него без удивления. [М. Ю. Лермонтов. Княгиня Лиговская (1836-1837)]

(25) Над тем, как функционирует бесписьменный язык, ему, по-видимому, вообще не приходилось задумывваться. [А. А. Зализняк. Лингвистика по А. Т. Фоменко // «Вопросы языкознания», 2000]

Заметим, что это значение появляется у слова по-видимому уже в XVIII в., ср.:

(26) Противъ самаго входу на горђ находятся остатки низменнаго вала, который по видимому для зашищенія сего удобнаго входу быль сдюланъ. [И. И. Лепехин (1770)]

(27) Ему не мудрено было меня помнить; и онъ, по видимому, не забывая ни стараго ни новаго состоянія своего, предавался поперемънно то робости, то спъси. [А. С. Шишков. Записки (1780-1814)]

Для значения слова по-видимому (как и для актуального на сегодня значения слова видимо) существенны следующие три обстоятельства. Во-первых, основанием для данного мнения могут служить данные любого рода, в том числе - не перцептивные (т.е. то, что нельзя «видеть» в прямом смысле). Так, фраза По-видимому она обиделась может быть произнесена скорее на основании фактов типа того, что она не отвечает на звонки или отказалась принять приглашение, чем на основании наблюдения ее выражения лица (в последнем случае уместнее кажется или похоже $)^{9}$. Во-вторых, высказываемое при помощи по-видимому мнение принадлежит говорящему (или, в нарративе - повествователю): оно не может передаваться другому лицу (т.е. по-видимому является «жестким эгоцентриком» по Е.В.Падучевой [11]). В-третьих, хотя высказываемое при помощи по-видимому мнение может быть разной степени уверенности, говорящий все же его придерживается, т.е. в некотором смысле принимает за истинное: по крайней мере, он не может продолжить высказывание с по-видимому словами ...а может быть / а на самом деле / но оказалось, что это не так - в отличие от таких выражений как с виду, на вид, на первый взгляд, такое продолжение легко допускающих.

Все эти обстоятельства представляют собой результат семантической эволюции слова noвидимому - от соответствующего его внутренней форме исходного значения 'на основании того, что Х видел, он сделал вывод, что вероятно Р’ (ср. пример (28) ниже), т.е. указания на вывод, сформировавшийся на основании некоторого зрительного впечатления, изначально не обладающего перечисленными выше ограничениями (назовем его значением «мягкой инференциальной оценкой»), к современному значению «жесткой инференциальной оценки» 'на основании каких-то данных я считаю, что скорее всего Р'.

Однако на протяжении всего XIX в. сохраняется возможность употребления по-видимому в исходном значении «мягкой инференциальной оценки», в котором оно вводит мнение, обладающее следующими признаками: (i) оно представляет собой интерпретацию зрительного впечатления; (ii) субъектом этого мнения является лицо, отличное от говорящего (повествователя); (iii) это мнение не охарактеризовано относительно истинности, т.е. является потенциально ложным.

Рассмотрим следующие примеры.

(28) Но Эльфрида падаетъ къ ногамъ его и требуетъ помилованія. Эдгаръ по видимому смягчается, уничтожсаетъ приговоръ свой, говорить о другомъ средствђ къ примиренію, не сказывая онаго, и велитъ Ательвольду сльдовать за нимъ въ лъсъ. Эльфрида думаетъ, что супругъ ея прощенъ; но скоро радость ея перемъняется въ отчаяніе, когда приходять ей сказать, что Король закололъ Ательвольда, вызвавъ его на поединокъ. [Н. М. Карамзин. Московской театръ // Московской журналъ. Часть VI, 1792]

\footnotetext{
${ }^{8}$ В [6: III, 159] у слова по-видимому отмечается единственное значение «вероятно, должно быть, весьма возможно». В [8] у этого слова различается несколько «контекстных конфигураций» значения в зависимости от его места в дискурсивной последовательности. В рамках нашего исследования эти различия не учитываются.

${ }^{9}$ Ср. обсуждение аналогичных примеров в [7: 92], [5: 303].
} 
(29) Все любили молодого учителя - Кирила Петрович за его смелое проворство на охоте, Марья Кириловна за неограниченное усердие и робкую внимательность, Саша - за снисходительность к его шалостям, домашние за доброту и за щедрость повидимому несовместную с его состоянием. [А. С. Пушкин. Дубровский (1833)]

В примере (28) вывод, что Эдгар смягчился и отменил свой приговор, принадлежит Эльфриде (признак (ii)), он сделан на основании наблюдения поведения Эдгара (признак (i)) и впоследствии он оказывается ложным (признак (iii)). В примере (29) мнение, что щедрость молодого учителя несовместима с его состоянием - это предположение, принадлежащее домашним Кирилы Петровича (признак (ii)), сделанное ими на основании имеющихся в их распоряжении сведений (как мы знаем, ошибочных, признак (iii)).

Употребления, где по-видимому вводит потенциально ложный вывод, который может быть кем-то сделан на основании зрительного впечатления или каких-то других данных, а говорящий считает (знает), что это не так, широко представлены в текстах XIX и начала XX в. Ложность этого вывода может быть выражена разными способами (но, а на самом деле и др.), cp. (опровержение вводимого словом по-видимому впечатления выделено подчеркиванием):

(30) В дверях, когда он уже оделся, показалась фигура Шацкого, - который, по-видимому, небрежно смотрел на публику, а на самом деле внимательно следил за Карташевым и не верил, что он действительно уйдет. [Н. Г. Гарин-Михайловский. Студенты (1895)]

(31) Вот он сидит, по-видимому, тихоня, а на самом деле ужасная язва. [А. М. Федоров. Его глаза (1913)]

(32) Работа с самого его детства шла, по-видимому, самая разнообразная, но, в сущности, все одна и та же, состоящая в том, чтобы во всех делах, представлявшихся ему на пути, достигать совершенства и успеха, вызывающего похвалы и удивление людей. [Л. Н. Толстой. Отец Сергий (1890)]

(33) Самый теперешний социализм французский, - по-видимому, горячий и роковой протест против идеи католической всех измученных и задушенных ею людей и наций $<\ldots>-$ самый этот протест $<\ldots>$ есть не что иное, как лишь вернейшее и неуклонное продолжение католической идеи. [Ф. М. Достоевский. Дневник писателя. 1877. Год II-й (1877)]

(34) Но они обречены на застой и на смерть, несмотря на всю, по-видимому, энергию их и тоску сердияа их. [Ф. М. Достоевский. Из записных тетрадей (1877)]

В более поздних текстах это значение представлено единичными примерами, ср.:

(35) Св[ятой] Исаак сказал: «Ничего нет каждому полезнее, как совет свой». А совет чуждый, хотя - по-видимому состоящий из благих и разумных слов, приносит душе лишь мучение, расстройство [монахиня Игнатия (Петровская). Святитель Игнатий - богоносец российский (1980-1990)]

(36) Моль заводится при сохранении сырья в сырых местах и хотя, по-видимому, она подбивает одну шерсть, но на самом деле она этим не ограничивается и портит лицо кожи. [Краткая энциклопедия скорняка, 1999]

(37) И вдруг засветил Руслану в глаз. - Ого, готов чувачок, - Глухой уже вызвал скорую. Он был, по-видимому, спокоен, но какое уж тут спокойствие. [Н. Б. Черных. Слабые, сильные. Часть вторая // «Волга», 2015]

$\mathrm{C}$ точки зрения современной нормы такое употребление является устаревшим: для выражения этого значения используются дискурсивные слова с виду, на первый взгляд, казалось бы и т.п.

\section{4 Эффект ближней семантической эволюции}

Как мы видим, на протяжении последних двух веков значение слов видимо и по-видимому довольно существенно изменилось. А именно, для слова видимо значение 'так, что это было видно' стало устаревшим, а слово по-видимому утратило значение потенциально ложного умозаключения, сделанного кем-то помимо говорящего на основании зрительного впечатления. При этом, наряду с контекстами, в которых эти слова в современном языке употреблены быть не могут (ср. грудь ее видимо подымалась в (7) или по-видимому, горячий и роковой протест в (33)), 
имеются и такие, в которых эти слова могут быть употреблены в современном значении. Это обстоятельство порождает «эффект ближней семантической эволюции» (см. [15]), т.е. ошибочное понимание этих слов в новом значении. Рассмотрим следующий пример:

(38) Мы условились драться за скирдами, что находились подле крепости, и явиться туда на другой день в седьмом часу утра. Мы разговаривали, повидимому ${ }^{10}$, так дружелюбно, что Иван Игнатьич от радости проболтался. «Давно бы так» - сказал он мне с довольным видом; - «худой мир лучше доброй ссоры, а и нечестен, так здоров». [А. С. Пушкин. Капитанская дочка (1836)]

Современный читатель прочитывает это предложение, как если бы здесь было сказано «По-видимому, мы разговаривали так дружелюбно, что...», где по-видимому вводит предложение говорящего (повествователя), не обращая внимание на неуместность такого понимания. На самом деле слово по-видимому в (38) употреблено в утраченном сегодня значении потенциально ложного вывода на основании зрительного впечатления (значение, выражаемое в современном языке словом $c$ виду); эта фраза выражает не предположение Гринева, а его утверждение, что его разговор со Швабриным имел видимость дружелюбного.

Об ошибочном понимании современным читателем значения слова видимо как вводного в примере (39) свидетельствует выделение его запятыми, в первоначальном издании отсутствующее ${ }^{11}$. Здесь слово видимо - это наречие, означающее '[Акулина привыкала к лучшему складу вещей], и это было видно'; ср. аналогичное значение слова приметно во второй части фразы.

(39) Акулина, видимо, привыкала к лучшему складу речей, и ум её приметно развивался и образовывался. [А. С. Пушкин. Барышня-крестьянка (1830)]

Существенно также, что описываемое впечатление принадлежит персонажу (Алексею), и оно является ложным: крестьянка Акулина - это на самом деле барышня Лиза, чей склад речей был и так достаточно хорош.

Эффект ближней семантической эволюции демонстрирует также пример (18).

\section{5 Заключение}

Слова по-видимому и видимо в современном русском языке являются довольно точными синонимами и представляют собой дискурсивные единицы - вводные слова, выражающие предположение говорящего, основанное на обработке каких-то данных (как перцептивных, так и любых других) и принимаемое им - за неимением лучшего - за истинное.

B XIX и частично в XX в. оба эти слова имели более широкий спектр значений: слово видимо употреблялось также в производной от пассивного причастия функции наречия со значением подтверждения истинности зрительного впечатления, а слово по-видимому (также в соответствии с его внутренней формой 'согласно тому, что видно') имело, в том числе, значение впечатления, которое, наоборот, может оказаться ошибочным. На протяжении последних двух веков оба эти значения были практически утрачены; оба слова имеют в современном языке единственное значение «уверенного предположения». Ход семантической эволюции единиц видимо и по-видимому обеспечивается тем обстоятельством, что обе границы - между непосредственной фиксацией увиденного и результатом вывода, сделанного на основании перцептивных данных, а также между истинным и ложным выводом на основании зрительного впечатления - являются проницаемыми.

Я благодарю Н.В.Перцова за содержательные замечания к первоначальному варианту статьи и любезно предоставленные мне ссылки на прижизненные издания пушкинских текстов, а также анонимных рецензентов Диалога за замеченные ими недостатки, которые были по возможности исправлены в окончательной версии статьи.

\footnotetext{
${ }^{10}$ В прижизненном издании («Современник», 1836, том IV, с. 85) написание раздельное: по видимому.

${ }^{11}$ См. Повъсти покойнаго Ивана Петровича БЪлкина, изданныя А. П. СПб. Печатано въ Типографіи Плюшара. 1831, c. 179. В целом, однако, наличие или отсутствие выделения запятыми в текстах XIX в. не может служить критерием выбора значения обсуждаемых слов, поскольку оно проводилось непоследовательно.
} 


\section{Литература}

[1] Апресян Ю.Д. (2008), От истины до лжи по пространству языка. // Логический анализ языка. Между ложью и фантазией. М.: Индрик. С. 23-45.

[2] Апресян Ю.Д. (ред.) (2014), Активный словарь русского языка. Т. 2. М., 2014.

[3] Арутюнова Н.Д. (1998), Язык и мир человека. М.: Языки русской культуры.

[4] Арутюнова Н.Д. (2008), Ви́денье и виде́нье // Логический анализ языка. Между ложью и фантазией. М.: Индрик. С. 92-105.

[5] Булыгина Т.В., Шмелев А.Д. (1997), Языковая концептуализация мира (на материале русской грамматики). М.: «Языки русской культуры», 1997.

[6] Евгеньева А.П. (ред.) (1999), Словарь русского языка. Под ред. А.П.Евгеньевой. В 4-х тт. 4-е изд., М., 1999.

[7] Иоанесян Е.Р. (1993), Классификация ментальных предикатов по типу вводимых ими суждений // Логический анализ языка: Ментальные действия. Москва, 1993. С. 89-95.

[8] Киселева К., Пайар Д. (2003), Механизмы семантического варьирования на примере группы единиц с корнем вид-: ВИДИМО, ПО-ВИДИМОМУ, ВИДНО // Д.Пайар (ред.) Дискурсивные слова русского языка: контекстное варьирование и семантическое единство. М., 2003. С.50-79.

[9] Кобозева И.М. (1988), Отрицание в предложениях с предикатами восприятия, мнения и знания // Логический анализ языка. Знание и мнение. Москва. С.82-97.

[10] Кустова Г.И. (2004), Вид, видимость, сущность // Сокровенные смыслы. Слово. Текст. Культура. Сборник статей в честь Н.Д.Арутюновой. М., 2004. С. 155-175.

[11] Падучева Е.В. (2018), Эгоцентрические единицы языка. М.: Языки славянских культур, 2018.

[12] Разлогова Е.Э. (1996), Модальные слова и оценка степени достоверности высказывания // Русистка сегодня, 1996/3. С. 21-47.

[13] Шмелев А.Д., Зализняк Анна А. (2017), Реверсивный перевод как инструмент лингвистического анализа дискурсивных слов // Компьютерная лингвистика и интеллектуальные технологии. По материалам международной конференции Диалог'2017. М., 2017. Т.2. С. 370-380.

[14] Зализняк Анна А. (2006), Многозначность в языке и способы ее представления. М.: «Языки славянских культур», 2006.

[15] Зализняк Анна А. (2012), Об эффекте ближней семантической эволюции. // PHILOLOGICA. Под ред. А. С. Белоусовой, И. А. Пильщикова. 2012, том 9, № 21/23, с. $11-22$.

\section{References}

[1] Apresyan Yu. D. (2008), From truth to falsehood in the space of language [Ot istiny do lzhi po prostranstvu yazyka], Logical analysis of language. Between lie and fantasy [Logicheskij analiz yazyka. Mezhdu lozh'yu i fantaziej] Moskva: Indrik. pp. 23-45.

[2] Apresyan Ju.D. (ed.) (2014), Active dictionary of Russian language [Aktivnyj slovar' russkogo yazyka]. Vol. 2.

[3] Arutyunova N.D. (1998), The language and the human world [Yazyk i mir cheloveka]. Moskva: Yazyki russkoj kul'tury, 1998.

[4] Arutyunova N.D. (2008), Vision and phantom [Vídenie i vidénie] Logical analysis of language. Between lie and fantasy [Logicheskij analiz yazyka. Mezhdu lozh'yu i fantaziej] Moskva: Indrik. pp. 92-105.

[5] Bulygina T.V., Shmelev A.D. (1997), Linguistic conceptualization of the world [Yazykovaya konceptualizaciya mira (na materiale russkoj grammatiki)]. Moskva: Yazyki russkoj kul'tury.

[6] Evgen'eva A.P. (ed.) (1999), Dictionary of Russian language [Slovar' russkogo yazyka]. In 4 volumes. $4^{\text {th }}$ edition.

[7] Ioanesyan E.R. (1993), Classification of mental predicates by the type of judgments they intruduce [Klassifikaciya mental'nyh predikatov po tipu vvodimyh imi suzhdenij], Logical 
analysis of language: Mental actions [Logicheskij analiz yazyka: Mental'nye dejstviya.] Moskva, pp. 89-95.

[8] Kiseleva K., Pajar D. (2003), Mechanisms of semantic variation on the example of a group of units with a root vid-: VIDIMO, PO-VIDIMOMU, VIDNO [Mekhanizmy semanticheskogo var'irovaniya na primere gruppy edinic s kornem vid-: VIDIMO, PO-VIDIMOMU, VIDNO], D.Paillard (ed.) Discursive words of the Russian language: contextual variation and semantic unity [Diskursivnye slova russkogo yazyka: kontekstnoe var'irovanie i semanticheskoe edinstvo]. Moskva, pp. 50-79.

[9] Kobozeva I.M. (1988), Negation in sentences with predicates of perception, opinion and knowledge [Otricanie $\mathrm{v}$ predlozheniyakh $\mathrm{s}$ predikatami vospriyatiya, mneniya i znaniya], Logical analysis of language. Knowledge and opinion [Logicheskij analiz yazyka. Znanie i mnenie]. Moskva, pp. C.82-97.

[10] Kustova G.I. (2004), View, visibility, essence [Vid, vidimost', sushchnost'], Secret meanings. Word. Text. Culture. Collection of articles in honor of N.D. Arutyunova [Sokrovennye smysly. Slovo. Tekst. Kul'tura. Sbornik statej v chest' N.D.Arutyunovoj]. Moskva, pp. 155-175.

[11] Paducheva E.V. (2018), Egocentric units of language [Egocentricheskie edinicy yazyka]. Moskva: Yazyki slavjanskikh kul'tur.

[12] Razlogova E.E. (1996), Modal words and the degree of reliability of the statement [Modal'nye slova i ocenka stepeni dostovernosti vyskazyvaniya], Rusistka segodnya [Russistics today], №3, pp. 21-47.

[13] Shmelev A.D., Zaliznyak Anna A. (2017), Reverse translation as a tool for linguistic analysis of discourse words [Reversivnyj perevod kak instrument lingvisticheskogo analiza diskursivnyh slov], Computational Linguistics and Intellectual Technologies: Proceedings of the International Conference Dialog 2017 [Komp'yuternaya lingvistika i intellektual'nye tekhnologii: Trudy Mezhdunarodnoj Konferencii Dialog 2017]. Moskva, Vol 2, pp. 370-380.

[14] Zaliznyak Anna A. (2006), Polysemy in language and ways of its representation [Mnogoznachnost' v yazyke i sposoby ee predstavleniya]. Moskva: Yazyki slavyanskikh kul'tur.

[15] Zaliznyak Anna A. (2012), On the effect of short-range semantic evolution [Ob effekte blizhnej semanticheskoj evoljucii], A.S.Belousova, I.A. Pil'shchikov (eds.) PHILOLOGICA. Vol 9, № 21/23, pp. 11-22. 